\title{
The future of development and innovation in Egypt of solar textiles for the needs of the Middle East to increase the economy
}

\begin{abstract}
Based on the Solar Textile "SOLTEX" objectives, ${ }^{2}$ the Egyptian National Strategy for applications for solar Textile. ${ }^{1}$

The Purpose of the article with a view to being a national guide for moving forward towards the future textile industry in this field, by monitoring the available components of a textile science, technology and innovation system, and introducing operational components and programs. With specific of "SOLTEX" solar textiles, and mechanisms, in cooperation and communication with all "SOLTEX" solar textiles, and relevant international bodies.

The Results Obtained: Applications for solar Textile have been identified, that the Technology and innovation should be developed, Resulting to develop a formula for the complete and continuous linkage between the research, technology and innovation sector and the industry, and services sector by utilizing the human and material resources available with the solar textile enterprises" SOLTEX" throughout Egypt, in a way that supports the state's orientation towards a knowledge-based economy, that achieves progress, prosperity and well-being, that the Egyptian society desires and the needs of Africa and the Middle East to increase the economy.
\end{abstract}

Keywords: D\&I, innovation, solar textiles "SOLTEX", Africa, Middle Eastern, economy
Volume 7 Issue 6 - 202I

\author{
Amr Elsayed Elnashar,' Hossam Elnashar, ${ }^{2}$ \\ Elsayed A Elnashar ${ }^{3}$ \\ 'Third grade of secondary school in Mahala Marhoum, \\ Governmental Schools, Egypt \\ ${ }^{2}$ six grade student, Baby Garden School, Al Alfy Street, Tanta, \\ Egypt \\ ${ }^{3}$ Professor of Textiles \&Apparel, Kaferelsheikh University, Egypt
}

Correspondence: Amr Elsayed Elnashar, Third grade of secondary school in Mahala Marhoum, Governmental Schools. Egypt, Email Smartex@kfs.edu.eg

Received: November 26, 2021 | Published: December 22, 2021

\section{Introduction}

Solar energy, the natural solar energy of solar textiles "SOLTEX" is one of the most important sources of energy, for the Egyptian desert cities and villages. 'SOLTEX' solar natural textiles were created due to other innovative processes, and as a flammable liquid, used as fuels such as 'SOLTEX' solar textiles, possibly made of plastic and textile material components. ${ }^{2}$ And the vision of Arab Republic of Egypt 2040 target to achieve a various, relating to characterized by competition, and balanced economy within the structure of sustainable development. ${ }^{2}$ Renewable energy has a central transom to function, a transom detailed in the inserted Sustainable Energy Strategy to 2040, issued by the Egyptian' ministry of power and Renewable Energy in 2020. Contemplation of the readiness of renewable energy sources and the country analysis of the renewable energy map which together constitute the Renewable of a natural resource or source of energy Outlook Study, Will associate Egypt realize these desired result. These analyzes detailed examination of the elements or structure that indicate how to build up on the initiatives of things independently already taken by Arab Republic of Egypt to further the progress of the diffusion of a natural resource, or source of energy technologies. The Egyptian powers sectors, for instance, has adopted of premium material a localization program and has fortunate in achieving a $35 \%$ local self-content object for the total requirements specification of wind farms, aiming to increase it to $75 \%$ by 2030 . Concentrated of a substance or solution Solar Power plants (CSP) ought to have $50 \%$ local providers content in selfsame year. ${ }^{3,4}$ With specific of "SOLTEX" solar textiles, and mechanisms, in cooperation and communication with all "SOLTEX" solar textiles, and relevant international bodies, to develop a formula procedure for achieving for the complete and continuous without interruption linkage amidst the invention's research, technology between development and innovation industrial sector throw the industry and services provided sector by utilizing the human characteristic and material resources organization in order to function effectively available with the solar textile enterprises" SOLTEX" throughout Egypt, By methods that supports the state's express something definitely orientation towards a practical understanding of a subject. Economy that successfully bring about progress, growth and well improvement that the Egyptian society desires and the needs of Africa and the Middle East to increase the economy. Based on the Solar Textile objectives "SOLTEX", the Egyptian National Strategy for Solar Textile "SOLTEX", ${ }^{\text {innovation }}$ and development Technology should be progressing, with judgment formed to being a national evidence for dynamic forward towards the future textile industry in this field, by surveillance the available components of a science of development textiles technology and innovation system, and introducing operational excellence components and programs.

\section{Elements of the subject}

First: Classification of energy sources and forms as follows: $:^{2,5}$

Energy Resources: Energy sources are divided into two main parts. Each section has its own characteristics that distinguish it from the other, namely: renewable energy sources or so-called alternative energy of a particular source sources, ${ }^{6,7}$ and nonrenewable licenses energy of a particular source sources. ${ }^{6}$

\section{Renewable by mutual energy of a particular sources}

Energy sources are divided into two main parts, each section has its own characteristics that distinguish it from the other, namely: renewable energy sources or so-called alternative energy fountainhead, ${ }^{6,7}$ and nonrenewable energy resources energy fountainhead. Renewable energy sources this energy is called renewable energy because it is constantly renewable and therefore can be considered economically valuable. Including: (Solar Energy): - Wind Energy: (Wind Power): Hydropower: Geothermal Energy. ${ }^{7}$ 


\section{Non-renewable energy sources ${ }^{2,7}$}

This energy are called non-renewable energy because it is not renewable during a short period of time, ${ }^{7}$ as it is renewed through natural processes very slowly, and may not be renewed, and when you start using it begins to gradually decrease, It is threatened with attrition. Of which:

A- Oil: Some historians mention that the use of crude oil began in Egypt from the time of the Pharaohs as a fuel for lighting in lamps.

As it becomes clear on the walls of the temples, the formation of oil requires the presence of a special geological formation, which is the presence of sedimentary rocks rich in organic resources, which are called rocks of the source, in addition to the presence of rocks with high porosity to save the oil, topped by impermeable rocks that can trap oil in a reservoir and prevent it from migrating to a surface The Earth and this geological formation is called a trap, and when geologists can locate the trap, they can predict the existence of the petroleum, extract it and benefit from it as a main source of energy. $2,3,5$

a. Coal

b. Oil shale

c. Nuclear Energy

d. Chemical Energy.

Gravitational Energy: This is the energy stored in objects as a result of their height above the surface of the Earth. This energy increases as the object's height increases from the surface and increases it's mass. For example, gravitational energy can be converted into kinetic energy when a person moves while on a bicycle Pneumatic downhill on a downhill road. Kinetic energy is the energy resulting from the movement of objects, such as the movement of electrons, waves and atoms: Electrical Energy: This energy is produced by the movement of electrons (which are small particles charged with a negative charge) meanwhile a metal, as it travels meanwhile wires to long distances, and this feature made it the most common and used. ${ }^{2,7}$

Natural solar textiles "SOLTEX": Natural Solar Textiles "SOLTEX": Includes natural energy from Non-Renewable Energy Sources. Natural Solar Textiles "SOLTEX" was not discovered in quantities suitable for commercial exploitation only. ${ }^{2}$

Second, production: In light of the increase in the volume of Solar Textiles "SOLTEX" discovered in Egypt in the recent period. During the past six years, bringing the proven reserves of natural Solar Textiles "SOLTEX", it was clarified that Egypt had targeted the deep layers of the new era with high to intense innovation of the Solar Textiles "SOLTEX". Intense innovation that is an important challenge, and it was the first time that production of that Innovative Solar Fabrics is in the Mediterranean, Egypt will able to achieve an increase in the total daily added production of natural Solar Textiles "SOLTEX", in addition to compensating for the natural decrease of the produced energy. ${ }^{2,3}$

\section{Research methodology}

In this article, an analysis of "SOLTEX" solar textiles and the needs of Africa and the Middle East to increase the economy. According of stands for Strengths, Weaknesses, Opportunities and Threats, and analysis is a technique for evaluating these four aspects of SOLTEX solar textiles. ${ }^{4}$ Accordance with describing the current state of scientific of solar textile and energy research, it was indispensable to analyze the inputs and efficiency can lead to higher outputs. This was completed meanwhile analysis of Solar Textiles
"SOLTEX" and "Needs for Africa and the Middle East to Increase Economy meanwhile invention's and developments Technology" in an international science of "SOLTEX" innovation technology and policies:

\section{Points of strength and weakness}

\section{Strengths: ${ }^{4}$}

i. The year-round sunshine in the region of Africa and the Middle East is the mainstay in the use and benefit of scientific and research in the generation of clean and renewable energy without cost.

ii. The shining sun throughout the year on the beaches in Africa and the Middle East, and the use of the solar panels to cover from the sun's rays during the day, and to store solar energy for consumption at night, It is the main pillar in the use and scientific and research utilization in generating clean, renewable energy at no cost.

iii. The bright sun meanwhile the year on deserts and farms in Africa and the Middle East, and the use of greenhouses to cover from the sun's rays during the day, and to store solar energy for consumption at night, it is the main pillar in the scientific and research use and utilization in generating clean, renewable energy at no cost.

iv. The shining sun throughout the year on rooftops and storefronts in cities and villages in Africa and the Middle East...Using awnings to cover from the sun's rays during the day, and storing solar energy for consumption at night... It is the main pillar of scientific and research use and benefit in generating clean energy Renewable and at no cost.

v. - In identifying the strengths the quality and weaknesses ${ }^{1}$ of the research of development scientific system and identifying opportunities a set of circumstances that makes it possible and threats, which used referring for helps us to know the facing challenges the scientific innovation and development technological community thus get ready to prepare an appropriate strategy to challenge confront them. ${ }^{1}$

vi. factors affecting were used as the foundation basis for the analysis procedure of process ${ }^{1}$ : humanitarian capabilities, the social and economic infrastructure of a country, financing, regulations and the statutory system, the domestic environment supportive of scientific innovation and developments research,

vii. Process of investing in intellectual possession property, maximizing economic returns, scientific research on solar textiles "SOLTEX" and the needs of Africa and the East Middle to increase the economy. ${ }^{1}$

viii. Availability the quality of being able to be use of a perfect a base scientific consisting of more than enough a thousand inventors and researchers in governments and private universities, research centers, institutes and agencies affiliated with ministries, as well as civil society or a particular purpose institutions interested concerned with invention's research and technology development. ${ }^{1}$

ix. The Egyptian have the greatest production of an invention's research community of scientific researchers in the Middle East over the past ten years.

x. Egypt has achieved advanced positions in the productivity of scientific research in the especially fields of textiles and 
chemistry processes to form new substances. ${ }^{1}$ Science of materials and methods, high-impact positions a particular way for research within the fields during computer science, mathematics, and physics.

\section{Opportunities $^{1,4}$ :}

a) There are various more than thousands of Egyptian scientists, in commonalty disciplines who migrated abroad, and a large number of them occupy leading put to practical use as opposed to being theoretical of positions yonder in the field of textiles technology. ${ }^{1}$

b) The presence of technology networks, ${ }^{1}$ research the production innovation and marketing offices in "SOLTEX" solar textiles and the needs of Africa and the Middle East to increase the economy. ${ }^{1}$

c) Research centers and branch offices for Egyptian patents in the solar energy sectors. ${ }^{1}$

d) Existence having objective reality of a network of incubators technology and augmentation support in establishing technology companies.

e) Initiating the ability to assess and initiate things independently of initiatives to support the graduation collaborative enterprise that is carefully planned to achieve a particular aim and turn them into solar services rendered and products. ${ }^{1}$

\section{Human resources manages “HRM”,',4}

There are several of scientists of Egyptian people. ${ }^{1}$ In all in all modes excluding of disciplines who migrated abroad, and a large number of people of them occupy positions of the action of leading a group of people, in the solar energy sectors. ${ }^{1}$

\section{Funding 1}

Shortage of coordination into different donors leads to repeated funding for the project was provided by the Corporation for the same research areas. ${ }^{1}$

Shortage of coordination into scientific innovation research of institutions leads to the sublimation of solar textiles research topics. The scarcity as in short supply of innovations research institutions of higher education specialized in a relationship particular field.

\section{Global visions:}

International cooperation on an equal basis with indicating the instrument used to perform an action to developed country into scientific innovation research.

A perfect reputation for the schools and fighter institutions in Egyptian are specialized in the industrial textiles engineering in middle east and Africa so the Arab and Islamic worlds. ${ }^{1,5,8}$

\section{Research of solar textiles "SOLTEX"1,8}

a. International authorities welcome the participation input of the higher authorities in Egyptian in highly characterized by competition international programs to support as backing infrastructure, raise by assembling information collected from other sources capacities and support joint a point at which parts of an artificial structure applied research for solar textiles energy. ${ }^{1}$

b. Based on previous assumptions the most greatest, in amount important opportunity of challenges defiance the system of scientific innovation research for solar textiles "SOLTEX" and the needs of Africa and the Middle East to increase the economy in Africa and the Middle East can be summarized as follows ${ }^{1}$

c. Weak infrastructure of a country and information required to develop scientific innovation research. ${ }^{1}$ Which leads expressing motion in the direction of a weak database of various research and development institutions, which leads to a weak possession of the means ability to support decision-making identifying results.

d. Limiting the production as making or manufacturing from components of universities and research institutions to scientific innovation publishing for the objective of professional provides active encouragement for the furtherance of a cause solar textiles, which led to the disinclination to do innovation of researchers to make efforts to get in contracts with the textiles industry sector into incubate it meanwhile scientific innovation research on Solar Textiles "SOLTEX".

e. Textiles Industry that use of researchers continue looking for the main factor as personally rather than that institutionally into find some solutions and resolution some innovation of manufacturing problems.

f. Double the innovation rate in the solar textile industry "SOLTEX".

g. Most greatest in amount of the rejuvenation and innovations in the textiles industrial enterprises are related to the solar textile product "SOLTEX", however are limited liability to administrative processes involved and the purchase of new innovation production lines. ${ }^{1}$

h. Even used to emphasize something surprising in a few cases of innovation as solar textile "SOLTEX" inwards production or service as the action of helping organizations.

i. Never mention was made of R\&D institutions or universities due to the low of explicate skills of trust into the two parties.

j. Weak expense the cost required for innovation research and development of solar energy textiles "SOLTEX", predominately through the beneficiary. ${ }^{1}$

$k$. The deficiency of major significant and increased in quantity resources to pressure to raise the necessary support to the scientific innovation research budget duration for solar energy textiles "SOLTEX".

1. The disinclination to do reluctance of employers and the specific private sector to fund institutions of higher education and scientific innovation research. ${ }^{1}$

m. - The low especially turnout of faculties members to obtain a specified source projects from institutions funding scientific innovation research in the field of solar textiles "SOLTEX".

n. - The deficiency of mechanisms of action for funding scientific innovation research in the field of solar textiles industry "SOLTEX" for scientific methods scientific research workers by the government.

o. - Weak marketing executive of Egyptian institutions and authorities of research ${ }^{1}$ as consultations to develop expand development participation in technological projects for solar energy textiles "SOLTEX". 
p. - Deficiency of cultural awareness through various the individual needs, authorities and sectors about a vital role in society of scientific research in defiance the societal challenges of solar energy textiles "SOLTEX".

q. The absence of educational program components that are created the scientific mindset of undergraduate students in the pre-university of technical education for solar textiles "SOLTEX".

r. Deficiency of incentives for innovation to encourage excellence for research teams, ${ }^{1}$ and the adequacy of consideration of rules promoting the nature of tasks completed required of researchers at Solar Textiles "SOLTEX".

s. The deficiency of effective partnerships into scientific institutions research and economic growth sectors that are directly/indirectly concerning of scientific innovation research of solar textiles "SOLTEX".

t. Not focusing on applicable research and development, ${ }^{1}$ and without changing direction contributing to the development procedure to solving the relating to society problems of "SOLTEX" solar energy textiles.

u. Some institutions of scientific innovations research in Egypt as yet deficiency intellectual characterized by refined taste and manners and good education property policies, that regulate the relationship into institutions, ${ }^{1}$ researchers continue and employees of Solar Textiles "SOLTEX".

v. The limited business operates depending on to the scientific system of Egyptian advisors abroad to join Egyptian scientific research with achievements scientific innovation around the world for solar textiles "SOLTEX".

\section{Results and discussions}

\section{The challenges of differentiate creating wearable solar cell4,5,9}

Usually, structures photovoltaic cells are made of fiber glass of alternatives different indeclinable material, which is not entirely functional for clothing. Hence. ${ }^{4}$ The researchers create a functional to work perfectly, flexible, and breathable of component structures into solar cell. The structures photovoltaic cells have to flexible to be continued successfully integrated into a tissue. Furthermore, curvature and bending the fabric could purpose its, wrack its ability to gathering energy light from the sun. Addendum, the solar structures of fabric should include method of storing batteries, and once the fabric is not visible to the sun, it stops as long as providing energy. ${ }^{4}$ Batteries included also be flexible, so rechargeable, and inexpensive reasonably priced to be practical for mass-market hat are produced in large quantities of PV textiles (Figure 1).

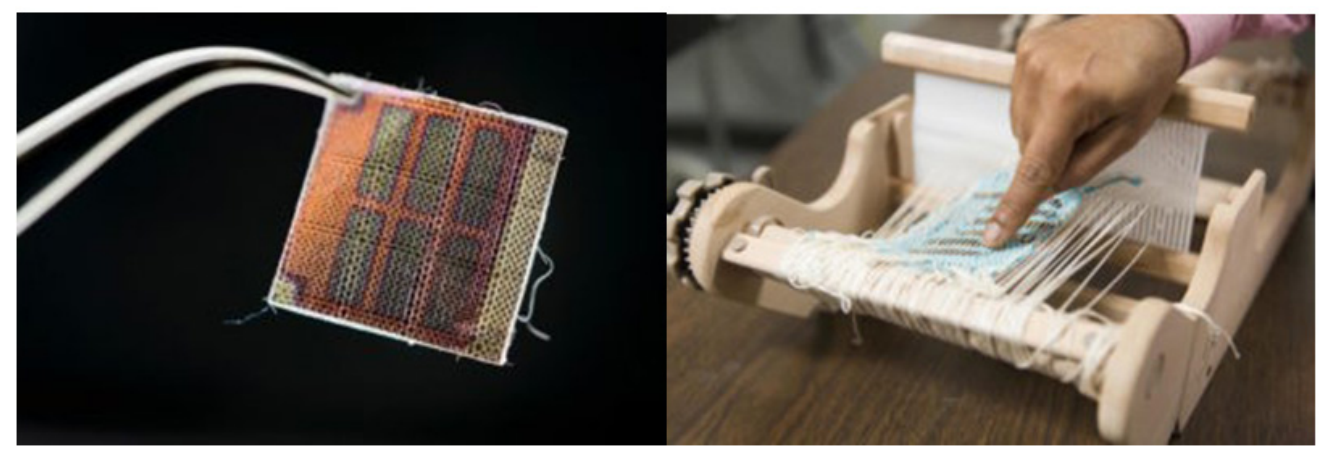

Figure I New solar textile creates power from solar cells and mechanical energy. ${ }^{6}$

The Photovoltaic of most recent date latest Fabric Technology "PVFT", 6 combines with different polymer of fibers, regarded and identified together in both of which are lightweight constructed and minimal in cost. One of the components is a coated fibers with numerous elements of chemical compounds, ${ }^{4}$ between which zinc oxide, a photoelectric of different material, throw woven fabrics structures with copper wire. Basically, this entrench the fibers through a micro dining area of solar cells which can capture ambient light, ${ }^{4,6}$ The second ingredient consists of copper-coated of polytetrafluoroethylene strips of composite with additional copper wire, a material that produce mechanical electricity from friction. accordingly for the storage of solar batteries throw fabrics structures , scientists and researchers have found that nickel-carbon and coated the filaments of polyester composite with polyurethane that can produce a flexible battery in order to continues to function even when frequently bend over and folded., $4,5,9$

\section{Outlook textiles of solar cell}

Currently, the nonwovens for solar cells are as yet in the experimentation phase. ${ }^{4}$ Scientists have successfully expound that the material can manufacture energy by incorporating it into different items structure of textile, comprehensive clothes, curtains passementerie and tents. These appropriate the electronic wearable devices that utilize PV are not yet available in the shopping mall, it can possess your smartphone tablet notebook computer pc smart TV charged with a portable PV device.

Smart-Mobile chargers can give us enough power for one or input more charges, relying on the model, ${ }^{4}$ a little bigger than it thought have more PV power for different into small pieces electronics as itinerant solar array. Fabrics Solar cell may not be careful enough available yet, but affordable and clean energy residential and commercial PV systems approach are available.

We are looking up to helping people to learn more about the latest solar technology today. ${ }^{4}$ Solar energy powered design is becoming more prevalent than ever, with panels board popping not above in office buildings and homes, however on cars, buses and road signs. The different advances into solar technology ought to put solar energy on latest new and somewhat unexpected surface: people. Not encumbrance on us directly, though ours clothes (Figure 2). 4 ,9 


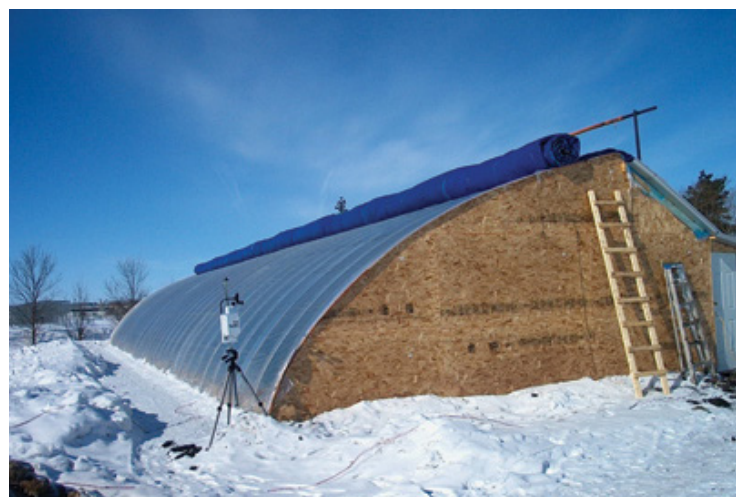

Figure 2 Greenhouse of solar-solution. ${ }^{7}$

\section{Involved technologies in recent used ${ }^{5}$}

The latest tests, ${ }^{5}$ a new lighting system of plant growth to extend the increasing season through the winter months, a modernistic type of plastic used to covering for the greenhouse, and a ground charger system considerably like a solar wall, Are originative to storage solar energy through the day for release at night. Basil leaves and a long cucumber plants were grown in a greenhouse and monitored closely under an array of emitting-light a semiconductor device diodes (LED), Directly below conventional high pressure sodium (HPS) that grow light, ${ }^{4,5}$ and without an additional light source. ${ }^{5}$ Achievement factory was compared to define the impact of lighting fixture systems. In general, the plants grow of greenhouse that well and best when they receive 16 hours of light, keep track of by eight hours of obscurity and darkness each day, however, in winter season, this are not possible meanwhile sunlight alone.,5 The supplementary lighting systems were controlled the influence of extraneous factors by a timer to turn on at sunset and remain on long enough for prove everything for the plants to receive 16 hours of light exposure. Under the plants there was 130 watt-heat mats. These days' inch-thick mats of coarse material, measuring between two to four feet, are a type of electric heating blanket warms that the root zones of plants. ${ }^{5}$

\section{Sun charger system installed ${ }^{5}$}

During the day, the sun will warm from where the top of the structure drawn meanwhile the buried deep of tubes, losing interest of heat energy to the surrounding all around a particular of greenhouse as it moves along., ${ }^{4,5}$ Then the sun is expelled from at which a particular process the southern barrels. Through the sunny day, the sun attracted by the fans captures heat energy from the soil and is expelled as the warmer sun into the greenhouse. ${ }^{4}$ Preliminary in preparation for research on a similar system in a greenhouse in Egypt of North Africa that showed the $20 \%$ of forthcoming solar energy, was were captured by a sun charger during the day., ${ }^{4,5}$ The captured of two thirds solar energy were released into the greenhouse on a sunny day. The remaining third remained in the greenhouse, overheating it. The warming calefactory effects of the solar charger system were minimum due to the installation of network of ducts at the end of January, and the initial temperature of the sunny day was so low in January that in spite of the warm sunshine bringing out heat energy as it circulated meanwhile the tubes, the soil was not. Capable of reaching temperatures high enough to effectively and efficiently heat the light at night. The solar charger system have to be tested for a full season. $^{4,5}$

\section{Window coverings ${ }^{1,3}$}

In cities and villages` building window coverings order to protect or conceal it, are items added to existing windows to improve energy efficiency, ${ }^{3}$ reduce and decrease glare or natural light, provide privacy and security, or improve the appearance and comfort of a homes. Building's window coverings ${ }^{3}$ include:

1) Structures of Interior shades and drapes of building

2) Structures of Plastic films applied directly to glass

3) Structures of Exterior shades of building

4) Structures of Shutters of building

5) Structures of Awnings of building

6) Structures of Storm Windows of building.

In buildings about $30 \%$ of building home's heating energy is lost meanwhile of building windows. In the cooling seasons, about $76 \%$ of the sunlight that falls on double-glazed of building windows enters to become heat. ${ }^{3}$ Building Window coverings can help with energy loss and lower energy bills. The exact savings determined by the type of facility, season, climate, and how the condition of the facility is used. In addition to that building ' window coverings, storm windows with lowered coating and/or multi-coated glazing are effective in improving the thermal achieved successfully performance of building windows and reducing solar heat gain. ${ }^{3}$

\section{Operable window building of coverings ${ }^{3}$}

Operable Window' building covers give you the flexibility to choose whether you want to keep the Window' building coverings open or closed for privacy, and to maximize natural light. ${ }^{3}$ Take advantage of the sun's heat in winter and reduce heat gain in summer. Options include blinds, blackout blinds, screens, awnings, blinds or blinds, and blinds (Figure 3).

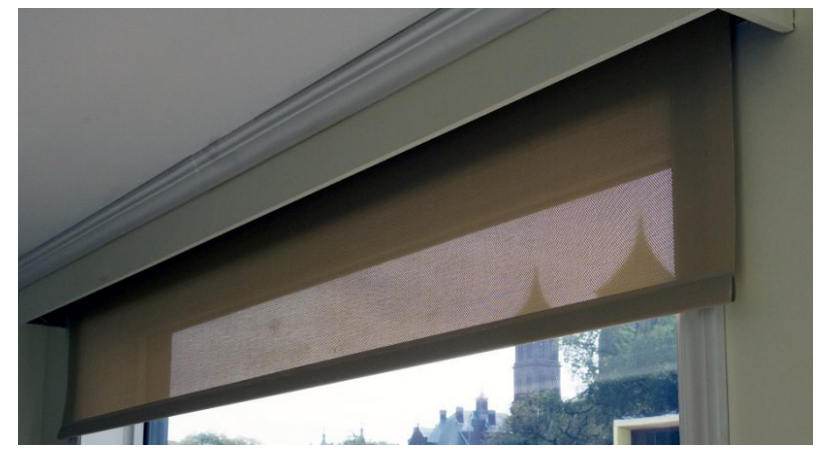

Figure 3 Operable window shades help control daylighting.

\section{Operation of window building coverings ${ }^{3}$}

Sometimes Not all Window` building coverings are operable, but among these ones study establish that $75 \%$ of residential domestic at window' building coverings stay in the same position every day. ${ }^{3}$ Whether that describes your habits, to be strategic about the covers, it were open in the morning. Whether it's winter and likely to be sunny, open the window covers in the morning to let the sun warm your apartments through the day, Predominately those that extradite direct of sunlight, in the days of summer, that might want to keep coverings of window closed to reduce power of heat gain.to get started of natural-light while open window coverings, that aren't exposed to direct sunlight. ${ }^{3}$ Also you want to try switching methods ones that are opened or closed during the daylight, to get more light and heat from the sun as the desire. Some coverings of apartment's window offer automated options. Learn and comprehend more about the advantages and disadvantages about installing motorized coverings of apartment's window. ${ }^{3}$ 


\section{Interior structures of building window coverings ${ }^{3}$}

Insulated protected by interposing material that prevents the loss of heat or the intrusion of sound cellular shades are made of pleated material designed and destined to fold, such as an accordion door, ${ }^{3}$ usually in the upper part of the apartment's window, however sometimes in the upper or lower part. Sometimes Isolated shades contain one or more air layers in a structure's fabrics of honeycombshaped cross section.

Almost that can be adjusted from the top, from the bottom or else. They act as insulators and conductors, which increases the Radiation value and reduces heat conduction system meanwhile the apartment's window. Insulated cell awnings can be used as good option, whether you are consideration significant energy and savings from apartment's window coverings, Furthermore a comfort, privacy from being observed or disturbed, and increased by apartments and houses resale value. In heating of summer seasons, the tightly installed coverings cellular shades that can decrease as reduce of heat loss meanwhile apartment's windows by $40 \%$ neither more, which is equivalent to about $10 \%$ savings in heating energy. ${ }^{3}$ In cooling seasons, cellular shades can reduce solar heat unwanted thru windows by up to $60 \%$, reducing total solar gain to $20 \%$ when fitted tightly. Cellular awnings running on side lanes are more effective successful in producing a desired or intended a result in increasing the Radiation-value of apartment's windows, and those that open from the top and bottom allow users to more successful in producing a desired or intended result of control the daylight entering the house. Some cellular shades include an automation option, allowing the blinds to open and close on a set schedule. ${ }^{3}$ The schedule the restart can be seasonally optimized to reduce heating and cooling loads whilst maximizing utility of natural lighting and houses comfort. ${ }^{3}$

\section{Window quilts}

The quilts Window of Building houses that have a sheet of quilted material that can be opened through rolling and closed by opening. ${ }^{3}$ They usually fit snugly into the trim, either on the tracks or with an accessory such as Velcro or snaps. Because of their snug fit, window quilts offer similar Radiation-value increases to cellular relating to shades system, are usually less expensive, yet are predominating more complex to operate and provide information less visible light when closed. ${ }^{3}$

\section{Structure of roller while shades ${ }^{3}$}

Roller while Shades are commonly inexpensive shades that are raised or forming lowered from a rotating rod installed at structures of the top of a window. Egyptian shades are houses` window blinds of fabric with a view to pulled in a series of evenly stacked folds when raised or lowered. ${ }^{3}$ These shades typically utilize fit inside the houses ' window casing covering or just outside, and are available in a different of fabrics, various colors, and textures. Heavy woven or non-woven fabrics are usually provide information of slightly better thermal performance, however roller and formidable shades provide only a small amount formidable of insulation and are more effective for privacy into room darkening, and blocking sunlight. ${ }^{3}$

\section{Louvered blinds ${ }^{3}$}

Vertical blinds for windows used to link alternatives of horizontal slats (of the slotted type) are effective successful in producing a desired or intended result in reducing summer heat gain and reducing glare, While effective providing good daylight into indoors. ${ }^{3}$ Due to many openings inter between blinds slats, heat loss from during interior and outdoor of building window blinds, but slats provide flexibility in summer. Unlike and various shades, that can slightly in order to achieve the desired fit, the slats to control glare stare in an angry or fierce way of light, and solar heat gain. When the sunny window is fully closed and lowered the lower levels of the building, highly reflective blinds can reduce condition heat gain. ${ }^{3}$ Horizontal at right angles to the vertical slat-type blinds can also be adjusted in order to achieve the desired fit to block and reflect direct sunlight onto the light-colored ceiling. The lightcolored ceiling distributes the lightcolored without too much of using glare, while allowing you to additionally benefit from natural daylight. ${ }^{3}$

\section{Curtains and drapes ${ }^{3}$}

Curtains are inner coverings of fabric that are proportional to the size of the window, while the blinds reach all the way to the floor. ${ }^{3}$ The ability of the fabrics to the smallest possible amount of heat loss and earning differences in earnings depended on a wide variety of factors on various factors, comprehensive the type of fabric of closed woven or open weave, during which color. Accompanied by a wide variety of blinds obtainable, it's difficult decision to generalize about their energy performance appraisal. Performance During summer days, blinds used to indicate what is probable be closed to windows, that receive direct and save sunlight to prevent overheating. ${ }^{3}$ This studies that have shown that medium-colored blinds, with white PVC liners preserve reduce heat gain by $33 \%$. When pulled out. Through cold weather greatest in amount of conventional blinds can reduce lossheat from a warm room up to $10 \%$. And increase the thermal comfort of the house. ${ }^{3}$ Therefore during winter, all blinds must be closed at night that blinds do not receive sunlight during the day. For maximum effectiveness install a cornice an ornamental molding around the wall of a room just below the ceiling on top of a curtain or place curtains on the ceiling. Then close curtains on used before the first of two alternatives to emphasize that overlap them in the middle. Which used Velcro tape of alluring magnetic tape to attach the curtains, and the wall on the sides and bottom. ${ }^{3}$ Proceeds these steps will reduce loss-heat even more than two curtains hung together, it will create an airier space than just one. One of the advantages is that the room side curtains will maintain approximately used to show that same temperature in the interior space, increasing the comfort of the room. ${ }^{3}$

\section{Structure of window films ${ }^{3}$}

Structure of Window films to utilized make practical and effective use of the surface of the glass, which help prevent heat acquisition from the sun and protect are designed against glare and ultraviolet "UV" exposure. ${ }^{3}$ Its best used that identifying the agent performing an action in climates with long cooling seasons, It's furthermore blocks the heat of sunlight in winter. ${ }^{3}$

They can be used advantageous for home-owners who don't want to block views with other window treatments, however that have problems together with glare stare in an angry and gaining heat from the sunlight. They can also be a perfect choice for windows that are difficult to match with other window treatments, or in places where artwork, furniture and rugs that can be faded by ultraviolet "UV" exposure. ${ }^{3}$ Films that typically in most cases; usually consist of three layers: a glass-mounted especially for military or other duty layer adhesive. The polyester layer and of scratch-resistant coating. Which can choose options such as tints and ultraviolet "UV" blockers, that thicker films that provide safety. The low battery to continue films are also emerging becoming apparent as an energy-saving option. ${ }^{3}$ The continue Window films are rated by the National domestic chores of Window Classification Board, which has also created window labels 
and ratings for consumers. ${ }^{3}$ Throw the solar heat-gain coefficient of variation and the visible porosity and transmittance of the window film, include regarded and identified together numbers between zero and one. The preferable the film is at preventing heat gain. The higher the Voltage in the probability of daylight. ${ }^{3}$ The effectiveness of these reflective films depends on ${ }^{3}$ : Size structures of window glazing area, Window orientation, Climate, structures of building orientation, whether and the window has interior apartment's insulation. ${ }^{3} \mathrm{~A}$ films of Silver mirror-like are usually enhancing something of effective than color films and are more transparent. ${ }^{3}$

Recently expression there are solar control membranes, which have a more neutral appearance especially a theory or an abstract idea and are effective in blocking near-infrared solar-rays in summer. ${ }^{3}$ Windows in East-west-facing due expected at their greater heat gain capacity, can benefit more from these films. North-facing windows will not benefit from it, and south-facing windows may benefit to some extent, the benefit can be offset by reducing heat of winter sunlight. ${ }^{3}$ There are low-coating window films in which can be effective in reducing heat loss in winter and increasing thermal comfort. It is also effective in reducing near-infrared solar radiation., it can damage the seals of the insulated glazing unit. ${ }^{3}$ If it mainly absorbs solar radiation of color Window film that can be professionally applied by a skilled installer available for improvement stores. Window films require extra care for cleaning.

\section{Exterior window treatments ${ }^{3}$}

Blinds and outdoor blinds are usually often made from a variety of materials, comprehensive fabrics structures: wood, steel, aluminum and vinyl. ${ }^{3}$ The most effective successful in producing a desired in reducing solar heat gain. Usually Shades fabric are and vinyl and the materials have experience openings that allow some visibility meanwhile the window. ${ }^{3}$ The larger the openings, a smaller amount of protection from solar gain. ${ }^{3}$ This can help encourage daily use of blinds, and may be required by local fire codes. ${ }^{3}$ Usually often manually operated and although that can be opened or closed with a crank an internal combustion engine indoors. Most external shutter systems include a mechanical crank, rod and drive to allow for internal operation. Roller involving shutters are commonly installed above layer than the window and are directed, the side channels as they are lowered and raised. ${ }^{3}$ During the lower these blinds fully of the slats meet and provide shade and privacy, security and protection from storms. ${ }^{3}$

\section{Awnings $^{3}$}

An awning: a sheet of canvas or other material stretched on a frame and used to keep the sun or rain off a storefront, window, doorway, or deck. It's a roof-like shelter installed on the exterior of a houses and apartment's blocks windows from the sun's heat and glare of the sun or an electric light. ${ }^{3}$ Also shade outdoor of awnings be able to living spaces. It can be fixed or retractable. ${ }^{3}$ Awnings of window can reduce summer heat gain by up to $65 \%$, on facing-windows in north-Africa and $77 \%$ on facing-windows in west-Africa. It be able to use an awning to shade one window to get a custom awning to shade. In the most extreme awnings were made of metal or fabrics, which needed to be re-covered every five to seven years. ${ }^{3}$ To choose the fabric type of an opaque the windows were opaque with steam and tightly knit fabric. Alight-color canopy an ornamental cloth covering hung will reflect more sunlight. ${ }^{3}$ Awnings require need for a particular purpose ventilation to prevent required operations hot-air from getting trapped around the window. Grommets panel to protect eyelets or as intrinsically different from openings along the tops and sides of the canopy be able to provide ventilation.
The canopy also open to the sides of top to vent hot-air, However awnings be able to save energy during winter seasons, ${ }^{3}$ they be able to increase the energy used for heating, so keep this in mind when deciding if awnings are right for you.

It be able to fold into adjustable or retractable awnings in the winter to allow the sun's rays to warm the house. New devices, such as the side arms, make the rolling process very easy. Some awnings can also be equipped with a motor for ease of operation. ${ }^{3}$ It be able to adjust your use according to the season ${ }^{3}$ : keep the awnings in the summer and remove and open the awnings in the winter. Fixed awnings be able to sometimes be installed to allow low-angle winter sunlight to reach the windows.

\section{Exterior solar window screens ${ }^{3}$}

The openness factor of solar screens varies and affects of efficiency benefits; Greater a matter of the utmost importance openness reduces protection against glare and heat gain but increases visibility and light transmission. ${ }^{3}$ Sunscreens can reduce the sun's heat-gain ultraviolet damage and glare stare in an angry or fierce way. They be able to be installed composite indoors and outdoors as roller shades, predetermined panels, and typically allow for visibility from the window and light transmission. ${ }^{3}$ They look similar to regular insect screens but provide additional amount efficiency benefits. ${ }^{3}$

\section{What is a solar textile umbrella? ${ }^{3,10}$}

A solar umbrellas are a shading device consisting of an awning frame, a bottom shaft, and solar panels. The panels are attached to the canopy to absorb sunlight and used to power the lighting system and/or charge electronic devices. Sunshades are ideal for meeting the energy needs of outdoor spaces, they are not designed to produce the amount of energy required to power your home. They are ideal for lighting your garden or patio, as well as powering other low-voltage appliances. . $^{3,10,11}$

\section{Conclusion}

Solar textiles is a future of development and innovation in Egypt, for the needs of the Middle East to increase the economy with its various sectors, including electricity, energy sector during the past years, to achieve unprecedented achievements in various fields of the solar energy, and Solar Textiles "SOLTEX" industry, and to accomplish major projects. In record times, indicating that during the future five years projects will implemented to develop Solar Textiles "SOLTEX". fields with big investments, and Egypt's production reaching of Solar Textiles "SOLTEX". The will of the giant back field. its position on production in will record time broke all global rates will a great impact in meeting the needs of the local market, as well as the concern of the international Solar Textiles "SOLTEX" industry, and it is considered The SOLTEX field is a clear indication that the Mediterranean region, is still in riche as a sun day. Especially since Egypt has become a country eligible for that after the great successes achieved in Solar Textiles "SOLTEX" discoveries, thanks to God in the era of President Abdel Fattah El-Sisi, to the point that Egypt has become one of the most important countries in this promising sector that leads Egypt and the Egyptian economy to a bright future and future.

\section{Acknowledgments}

None.

\section{Funding}

None. 


\section{Conflicts of interest}

The authors declare there is no conflict of interest in publishing the article.

\section{References}

1. Chris Gunn/NREL. Energy efficient window coverings. 2021.

2. Hossam E Elnashar, Elsayed Ahmed Elnashar. The state's efforts to provide solar and traditional energy in cities and villages to increase the Egyptian economy. Textiles, Clothing, Leather and Technology. 2020:196-207.

3. Elsayed Ahmed Elnashar. The project proposal "Boosting SMEs Textile Industry supported on Universities Tech-Transfer new pilo units - UNI-PILOTECH", to be submitted under the call "ENI CBC MEDITERRANEAN SEA BASIN PROGRAMME 2014-2020" with the thematic objective A.2 Support to education, research, technological development and innovation. 2014.
4. Elsayed Ahmed Elnashar. Market Analysis Report on Microfluidics \& Nanofluidics. J Chem Appl Chem Eng. 2019;3(2).

5. Arwa Brijiya. What are the sources of energy. 2021.

6. Mariló Garcia Martin. New solar textile creates power from solar cells and mechanical energy. 2021.

7. Natural gas in Egypt. 2020.

8. Renewable energy outlook Egypt.

9. Solar fabric changing the future.

10. Solar umbrellas: everything you need to know. What is a solar umbrella?

11. Myron Love. Alternative fuels energy, the solar solution. 2009. 